In 2003, the Honour Society of Nursing, Sigma Theta Tau International and Nursing Spectrum sponsored an "Innovations in Clinical Excellence" contest to recognise exemplars of evidence-based nursing practice. The following is 1 of 5 winning entries, which is published with permission of the Honour Society of Nursing, Sigma Theta Tau International.

\title{
Evidence-based quality improvement project for determining appropriate discontinuation of peripheral intravenous cannulas
}

\section{PRACTICE PROBLEM}

With the increased acuity of today's patients, the number of patients receiving intravenous (IV) therapy is much higher than the 25 million estimated over a decade ago by Maki and Ringer. ${ }^{1}$ Performing venipuncture for the purpose of inserting a peripheral IV line is painful to the patient and costly to the institution. In many instances, patients have several unsuccessful attempts before a peripheral line is successfully inserted. Current hospital policy was recently changed from 72 to 96 hours of dwell time based on recommendations from the Centers for Disease Control (CDC). As in our previous policy, IV cannulas must be replaced at least every 96 hours regardless of the clinical condition of the IV site. A variety of symptoms are associated with IV phlebitis including tenderness, pain, erythema, oedema, increased warmth, palpable cord, and purulent drainage, with subtle differences in the definition of phlebitis among studies. Valid assessment of IV sites is dependent on the use of a valid and reliable phlebitis scale. IV phlebitis may develop while the IV is in situ and up to 96 hours after the IV is removed. ${ }^{2}$ It is the premise of this evidence-based quality improvement project that IV cannulas should be removed based on clinical evaluation rather than a pre-set time.

\section{TYPE OF EVIDENCE USED}

Internal and external data were used for the project. Quarterly data on the appearance of IV sites have been collected on our postoperative cardiac surgery unit for the past 4 years. Studies that examined IV dwell time and studies that used a phlebitis scale were evaluated.

\section{METHOD USED TO OBTAIN AND REVIEW EVIDENCE Medline and CINAHL are used to continuously update the external evidence. Each article that addresses dwell time is reviewed, using the Schultz guidelines, to evaluate its scientific merit and utility. The studies are examined for their definition of phlebitis, variables predictive of phlebitis development, type of infused medication or infusate, and length of dwell time. Studies are synthesised in integrated tables based on these variables. Phlebitis scale studies are examined for scale development methods and reliability and validity evaluation. A published version of a phlebitis scale, the Visual Infusion Phlebitis Scale (VIP) ${ }^{3}$ was found, although it had limited psychometric evaluation.}

\section{PLANNED STRATEGY FOR IMPROVEMENT}

An evidence-based practice team was formed on the unit. The team decided to monitor IV sites for 1 month, using the VIP as the objective measurement of phlebitis. Inter-rater reliability was established at 0.85 among the data collectors. In the first monitor, the phlebitis rate was determined to be $8.5 \%$, higher than the $5 \%$ recommended by the CDC. It was also discovered that hospital policy of changing the IV site every 72 hours was not followed if the patient was going home soon or if the patient was known as a "hard stick." There were also about $20 \%$ of the IVs that did not have start date labels, making it impossible to determine when the catheters needed to be changed.

\section{HOW THE STRATEGY WAS IMPLEMENTED}

Using the baseline information, a quarterly monitoring system was established. Coloured labels were ordered, and education on the hospital policy was conducted. Annual inter-rater reliability of 0.85 was established. The team continued to review the research literature annually for evidence-based changes in practice.

\section{METHOD OF EVALUATION}

Quarterly IV site information is collected, and IV sites are objectively measured using the VIP scale. Data are reported to the unit.

\section{OUTCOMES/RESULTS}

Our annual phlebitis rates since 1998 have ranged from 8.5-22.2\%. In 2002, our rate was $11.4 \%$. In 2002, the CDC recommended that peripheral IV sites could remain in situ up to 96 hours. Our policy was changed to reflect the CDC recommendation. In 2002, $20 \%$ of the IVs on this unit had dwell times greater than 96 hours. Of these IVs, $4.6 \%$ had signs and symptoms of phlebitis.

\section{LESSONS LEARNT}

Even with continuous attention to IV site phlebitis, signs and symptoms of phlebitis can be an issue. It is suspected that many of the medications added to peripheral IVs are so damaging to the veins that phlebitis quickly followed infusion. The research literature does not provide substantive evidence on practical solutions for reducing IV phlebitis in our rapidly changing healthcare scene. Use of an objective scale to measure IV phlebitis supports the clinical judgment of the nurse; the team is currently in the process of initiating its use on all units. We are also commencing a study to determine if an objective assessment scale, rather than dwell time, can be safely used to determine when an IV site should be discontinued.

ALYCE A SCHULTZ, RN, PhD, FAAN PAULETTE GALLANT, RNC, BSN Maine Medical Center, Portland, Maine, USA

1 Maki DG, Ringer M. Risk factors for infusion-related phlebitis with small peripheral venous catheters. A randomized controlled trial. Ann Intern Med $1991 ; 114: 845-54$

2 Lundgren A, Wahren LK, Ek AC. Peripheral intravenous lines: time in situ related to complications. J Intraven Nurs 1996;19:229-38.

3 Jackson A. Infection control-a battle in vein: infusion phlebitis. Nurs Times 1998;94:68, 71 . 